\title{
Pharmacological and non-pharmacological recanalization strategies in acute ischemic stroke
}

\section{Anita Frendl and László Csiba*}

Department of Neurology, University of Debrecen Medical and Health Science Center, Debrecen, Hungary

\section{Edited by:}

David S. Liebeskind, University of

California Los Angeles, USA

\section{Reviewed by:}

Ru-Lan Hsieh, Shin Kong Wu Ho-Su Memorial Hospital, Taiwan

Turgut Tatlisumak, Helsinki University

Central Hospital, Finland

\section{${ }^{*}$ Correspondence:}

László Csiba, Department of Neurology, University of Debrecen Medical and Health Science Center, Nagyerdei Körút 98, P.O. Box 48,

Debrecen, Hungary.

e-mail: csiba@dote.hu
According to the guidelines of the European Stroke Organization (ESO) and the American Stroke Association (ASA), acute stroke patients should be managed at stroke units that include well organized pre- and in-hospital care. In ischemic stroke the restoration of blood flow has to occur within a limited time window that is accomplished by fibrinolytic therapy. Newer generation thrombolytic agents (alteplase, pro-urokinase, reteplase, tenecteplase, desmoteplase) have shorter half-life and are more fibrin-specific. Only alteplase has Food and Drug Administration (FDA) approval for the treatment of acute stroke (1996). The National Institute of Neurological Disorders and Stroke (NINDS) trial proved that alteplase was effective in all subtypes of ischemic strokes within the first $3 \mathrm{~h}$. In the European cooperative acute stroke study III trial, intravenous (IV) alteplase therapy was found to be safe and effective (with some restrictions) if applied within the first 3-4.5 h. In middle cerebral artery (MCA) occlusion additional transcranial Doppler insonication may improve the breakdown of the blood clot. According to the ESO and ASA guidelines, intra-arterial (IA) thrombolysis is an option for recanalization within $6 \mathrm{~h}$ of MCA occlusion. Further trials on the IA therapy are needed, as previous studies have involved relatively small number of patients (compared to IV trials) and the optimal IA dose of alteplase has not been determined (20-30 mg is used most commonly in $2 \mathrm{~h}$ ). Patients undergoing combined (IV + IA) thrombolysis had significantly better outcome than the placebo group or the IV therapy alone in the NINDS trial (Interventional Management of Stroke trials). If thrombolysis fails or it is contraindicated, mechanical devices [e.g., mechanical embolus removal in cerebral ischemia (MERCI)- approved in 2004] might be used to remove the occluding clot. Stenting can also be an option in case of acute internal carotid artery occlusion in the future. An intra-aortic balloon was used to increase the collateral blood flow in the Safety and Efficacy of NeuroFlo ${ }^{\mathrm{TM}}$ Technology in Ischemic Stroke trial (results are under evaluation). Currently, there is no approved effective neuroprotective drug.

Keywords: intravenous thrombolysis, intra-arterial thrombolysis, acute stroke, mechanism of recanalization, thrombectomy, alteplase, stroke unit, therapeutic time window

\section{INTRODUCTION}

Stroke is the third most common cause of death and it is the most commonly disabling disease. The care of stroke patients is challenging, because there is no easy method to rapidly establish the diagnosis at the patient's home like in some of the acute myocardial infarction cases (e.g., EEG). It is also impossible to distinguish hemorrhagic strokes from ischemic strokes based solely on clinical symptoms; for that a brain CT must be performed. The time window for therapy is short and none of the neuroprotective agents have been proven to be effective yet.

The effective treatment of ischemic strokes today relies on rapid mechanical endovascular or pharmacological revascularization of the affected areas. The 1995 National Institute of Neurological Disorders and Stroke (NINDS) trial represented a breakthrough, as it was the first to prove in a randomized study that fibrin-specific agents could lead to both revascularization and clinical improvement in all subtypes of ischemic stroke, advancing stroke therapy beyond the previously used non-fibrin-specific drugs (The National Institute of Neurological Disorders and Stroke rt-PA Stroke Study Group, 1995). tissue type-plasminogen activator (t-PA) was approved by the Food and Drug Administration (FDA) in 1996 and is widely used for the treatment of ischemic strokes.

Because pharmacological thrombolysis is not $100 \%$ successful, mechanical thrombectomy has also attracted attention in the last few years. These techniques use intra-arterial (IA) devices to remove the clot or sclerotic debris from the occluded artery, which remain insoluble following thrombolysis.

In this review we discuss the:

- importance of early revascularization in acute ischemic stroke,

- experience with fibrinolytics, 
- methods of intravenous (IV), IA, and combined (IV + IA) thrombolysis,

- recent results with mechanical revascularization (recanalization) techniques.

\section{TIME IS OF ESSENCE: THE IMPORTANCE OF EARLY REVASCULARIZATION (RECANALIZATION)}

The size of the ischemic lesion is proportional to the caliber of the occluded artery, and to the duration of the occlusion, and will only be reduced by the blood flow available through the collaterals. A general rule (with many exceptions) is that distal occlusions (e.g., middle or anterior cerebral artery) have a higher risk for cerebral infarction than proximal ones [e.g., internal carotid artery (ICA)] because the latter has more collateral blood flow available to compensate. A sudden arterial occlusion triggers the development of the ischemic cascade.

Decreased blood perfusion of the brain results in oxygen and glucose deficit. The consequences are extracellular calcium and sodium influx into the intracellular space and potassium efflux. Calcium influx activates lipase enzymes and the release of excitatory amino acids. Neurotransmitters and free radicals are produced followed by cytokine release and several additional catabolic mechanisms are induced. Intracellular ion changes occur within a short time; this phenomenon can be used for detecting the abnormal cellular water movement within minutes of the symptom onset of ischemic strokes using diffusion MRI (Kuroiwa et al., 2007).

Therapeutic strategies were significantly altered by the development of the theory of the "ischemic penumbra" (Figure 1). This hypothesis does not consider the ischemic region a homogeneous dead tissue with sharp edges separated from the intact tissue (Astrup et al., 1981; Csiba et al., 1983, 1985). Rather, only the ischemic core, where the blood flow is below the critical value of $7.7-14 \mathrm{ml} / 100 \mathrm{~g} / \mathrm{min}$, is considered to be irreversibly damaged. The region surrounding this area has functional deficit ("electric silence") with otherwise preserved integrity of the tissues (ischemic penumbra) and is an area at risk. This is the area we aim to salvage during stroke interventions. The success of our rescue efforts will depend on the duration of the ischemia, on the degree of revascularization and on additional factors such as blood pressure, serum glucose, etc. (Segura et al., 2008).

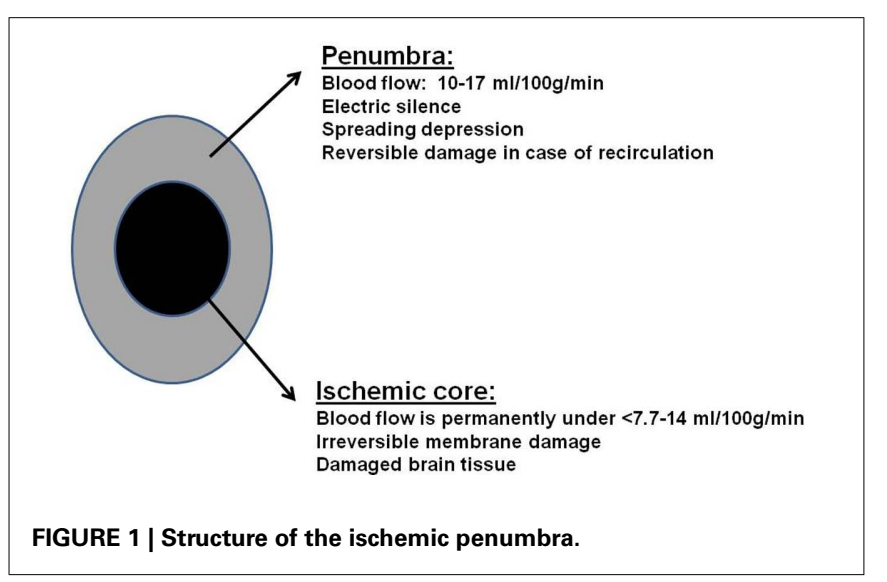

Both animal and human studies proved that the size of the penumbra (the salvageable area at risk) is shrinking as time goes on while the area of permanent damage is expanding. Therefore recanalization of the occluded artery should happen within a few hours after the onset of the focal ischemic stroke, otherwise 120 million neurons, 830 billion synapses, and $714 \mathrm{~km}$ axons die each hour (Saver, 2006).

\section{FIBRINOLYTIC DRUGS}

Agents available for IV or IA thrombolysis are: streptokinase, urokinase, alteplase, pro-urokinase, reteplase, tenecteplase, and desmoteplase.

\section{FIRST GENERATION FIBRINOLYTICS (STREPTOKINASE, UROKINASE)}

These agents only have historical importance (Cornu et al., 2001). They are not fibrin-specific. They induce fibrinolysis but they also decrease the level of fibrinogen, coagulation factors, and von Willebrand factor in the blood. Streptokinase, an enzyme secreted by several species of streptococci, can activate human plasminogen. Since it has immunological side effects (allergic reactions) and increases the risk of intracranial hemorrhage, it is no longer used for thrombolysis. Urokinase was also tested for both IV and IA thrombolysis, but it has not significantly improved clinical outcomes (Murray et al., 2010).

\section{SECOND GENERATION FIBRINOLYTICS (ALTEPLASE, PRO-UROKINASE)}

Alteplase and pro-urokinase are more fibrin-specific and have no immunological side effects compared to the previous group. Alteplase (rt-PA) is the only FDA approved fibrinolytic drug in acute ischemic stroke. It has a short half-life (4-6 min) but unfortunately it also has some neurotoxic side effects by activating a metalloproteinase. This enzyme modulates the blood-brain barrier, which results in an increased risk for intracerebral bleeding and brain edema (Micieli et al., 2009).

Pro-urokinase (half-life $7 \mathrm{~min}$ ) has been also tested in clinical trials, but unfortunately despite the good clinical results it has not received FDA approval yet. The prolyse in acute cerebral thromboembolism II (PROACT II) trial (Furlan and Abou-Chebl, 2002) compared the efficacy of IA pro-urokinase treatment with IV heparin in middle cerebral artery (MCA) occlusion. Recanalization rate was $66 \%$ in the pro-urokinase, and $18 \%$ in the heparin group, while $40 \%$ of the cases in the pro-urokinase and $25 \%$ in the heparin group had good clinical outcome (less than two on the modified Rankin Scale; Furlan and Abou-Chebl, 2002) (Table 3).

\section{THIRD GENERATION FIBRINOLYTICS (RETEPLASE, TENECTEPLASE)}

Since rt-PA might damage the blood-brain barrier, there are further efforts for developing fibrinolytics with fewer side effects. Reteplase and tenecteplase are modified forms of alteplase with longer half-life and have only been applied in trials yet.

The first prospective human clinical trial evaluated the safety and efficacy of IA reteplase treatment in 16 patients with ischemic stroke who were poor candidates for IV alteplase therapy. Near complete or complete recanalization was observed after treatment in $88 \%$ of the patients (Qureshi et al., 2002).

In a preliminary safety trial different doses of IA reteplase were combined with IV administered abciximab (platelet aggregation inhibitor, glycoprotein IIb/IIIa). The patients were treated 
between 3 and $6 \mathrm{~h}$ following the onset of their symptoms. There was one symptomatic intracerebral hemorrhage and 13 successful recanalization among the 20 patients treated. Thirteen patients demonstrated early neurological improvement and favorable outcome was observed in six patients after 1 month (Qureshi et al., 2006).

Tenecteplase has a longer half-life $(17 \mathrm{~min})$ and is more fibrin-specific than alteplase.

In another study, low-dose tenecteplase $(0.1 \mathrm{mg} / \mathrm{kg})$ was applied IV in a small group of patients $(N=15)$ between 3 and $6 \mathrm{~h}$ after the onset of cerebral arterial occlusion; patients had a perfusion deficit of at least $20 \%$ larger than the infarct core (perfusion/angiographic $\mathrm{CT} / \mathrm{MR}$ ). Their results were compared to the outcome of 35 patients treated within the first $3 \mathrm{~h}$ with rt-PA following the standard selection criteria (Parsons et al., 2009). Tenecteplase showed significantly higher recanalization rate compared to alteplase (74 vs. $44 \%$ ). Despite the fact that the treatment was started later and the symptoms were more severe in the tenecteplase-group, patients showed better improvement at $24 \mathrm{~h}$ after the therapy than those patients who were treated with alteplase. Four of the alteplase treated patients and none of the tenecteplase treated patients had parenchymal hematoma at $24 \mathrm{~h}$.

Haley et al. (2005) found the dose of $0.1-0.4 \mathrm{mg} / \mathrm{kg}$ of tenecteplase safe to be used in acute stroke. Eighty-eight patients were treated within the first $3 \mathrm{~h}$. The lower doses of tenecteplase $(0.1,0.2$, or $0.4 \mathrm{mg} / \mathrm{kg})$ caused only asymptomatic intracerebral bleeding (in $8-32 \%$ of the cases in the separated subgroups), while the higher doses $(0.5 \mathrm{mg} / \mathrm{kg})$ caused both asymptomatic and symptomatic intracerebral bleeding (in 13 and $23 \%$ of the 13 treated patients). According to the modified Rankin scale tenecteplase showed similar results as alteplase at the 3-month follow-up period.

\section{FOURTH GENERATION OF FIBRINOLYTICS (DESMOTEPLASE)}

The fourth generation fibrinolytics are produced by genetic methods.

Desmoteplase (more fibrin-specific, has no neurotoxicity) has been tested in the desmoteplase in acute stroke (DIAS) 2-4 trials (Paciaroni et al., 2009). DIAS was a randomized, placebocontrolled trial with a 3 to 9-h time window (Hacke et al., 2005) for treatment eligibility. Patients with moderate symptoms and diffusion/perfusion mismatch on the MRI were randomized into placebo and fix dose of IV desmoteplase groups. A symptomatic intracranial hemorrhage was observed in $30.8 \%$ of the patients in the high-dose $(37.5$ or $50 \mathrm{mg}$ ) and $23.5 \%$ of the patients in the low-dose $(25 \mathrm{mg})$ group in the first part of the trial. Subsequently, the study was continued with considerably lower dosages (90 and $125 \mu \mathrm{g} / \mathrm{kg}$ ). There the occurrence of symptomatic intracranial bleeding in the desmoteplase group was found to be only $2.2 \%$. However, the results of DIAS-2 trial could not support these favorable findings. In the DIAS-2 trial almost 200 patients were randomized into groups treated with different doses of desmoteplase. Inclusion criteria of the patients was diffusion/perfusion mismatch on MR/CT. Treatment was initiated between 3 and $9 \mathrm{~h}$ after the onset of stroke. Unfortunately, neither the 90 nor the $125-\mu \mathrm{g} / \mathrm{kg}$ dosages were found to be effective. Additionally, mortality was higher in the group treated with $125 \mu \mathrm{g} / \mathrm{kg}$ compared to both the placebo-treated group and the group which received the $90-\mu \mathrm{g} / \mathrm{kg}$ dose (Liebeskind, 2009). The rate of bleeding was $4.5 \%$ in the higher dose and 3.5\% in the lower dose treatment group and $0 \%$ in the placebo group. The DIAS- 3 and -4 trials are still ongoing. They are comparing the effect of placebo with IV desmoteplase treatment $(90 \mu \mathrm{g} / \mathrm{kg}$ dose $)$ given between the first 3-9 h after acute stroke.

In conclusion: at present the evidence is strongest for alteplase to be a clinically effective fibrinolytic in acute stroke, but research is still ongoing to find a more fibrin-specific agent with shorter half-life and less neurotoxic side effects.

\section{INTRAVENOUS FIBRINOLYSIS IN THE CLINICAL PRACTICE}

The NINDS trial produced a real breakthrough in fibrinolytic therapy. It proved the efficacy of rt-PA (alteplase) therapy in all subtypes of ischemic stroke. It also proved that the benefits of thrombolysis (rt-PA) extend beyond 1 year after the treatment (Kwiatkowski et al., 1999).

However, the 3-h time window for treatment has proven to be too short in clinical practice. Therefore, several subsequent studies have investigated the feasibility of a wider, but still safe time window.

The results of European cooperative acute stroke study (ECASS-III), a placebo-controlled trial, using IV rt-PA in the 3 to 4.5-h time window, were published in 2008 (Saver et al., 2009). This placebo-controlled trial proved the safety of IV thrombolysis within the first $3-4.5 \mathrm{~h}$ following ischemic stroke with patient listed below excluded from the trial.

- Younger than 18 or older than 80 years

- Severe neurological symptoms National Institute of Health Stroke Scale (NIHSS) > 25

- Taking anticoagulant (irrespectively of hemostatic parameters)

- History of diabetes mellitus and a previous stroke

In this study excellent clinical outcomes ( 0 or 1 point on the modified Rankin Scale) were more frequent in the rt-PA treated group than in the placebo group ( 52 vs. $45 \%, p=0.04$ ) 3 months after treatment. The mortality in the rt-PA treated group was not significantly different from that of placebo group (17\% in the treated group a $21 \%$ in the placebo group). While, symptomatic intracranial bleedings were more frequent in the t-PA group (2.4 vs. $0.2 \%$, $p=0.001)$.

Before initiating IV thrombolysis, the cost-benefit ratio must be calculated. The inclusion and exclusion criteria must be followed strictly (Table 2). When doing so, one has to bear in mind that 32 patients out of 100 thrombolysed will likely to show improvement and only three is likely to have harm (Saver, 2004). Follow-up studies also support the fact: the earlier the thrombolysis is performed the better clinical improvement can be achieved. One of two patients will likely become symptom-free or have minimal residual symptoms if treated with IV thrombolysis (Marler et al., 2000; Saver et al., 2010) within the first hour following a stroke. This ratio drops to 1 out of 4 if treated between 60 and 90 min after the onset of stroke, and 1 out of 9 between the first 90-180 min, further diminishing to 1 out of 21 patients if treatment is delayed to $180-270 \mathrm{~min}$. Time lost is brain lost! 
Table 1| Recommendations for the specific treatment of acute ischemic stroke.

Intravenous rt-PA $(0.9 \mathrm{mg} / \mathrm{kg}$ body weight, max. $90 \mathrm{mg})$ is recommended within the first $3 \mathrm{~h}$ (in selected cases also between the first 3 and $4.5 \mathrm{~h}$ ) of the ischemic stroke. $10 \%$ of the calculated dose is given as an iv. bolus injection, 90\% is given under 60 minutes as an iv. infusion.

Lower blood pressure under $185 / 110 \mathrm{mmHg}$ before initiating thrombolysis. Intravenous rt-PA may be used in patients with seizures at stroke onset, if the neurological deficit is related to acute cerebral ischemia.

Age: intravenous rt-PA may also be administered in selected patients under 18 years and over 80 years of age.

Intra-arterial treatment of acute MCA occlusion within a 6-h time window with rt-PA is an option.

Acute basilar occlusion: intra-arterial thrombolysis is recommended for selected patients and intravenous thrombolysis is acceptable even after $3 \mathrm{~h}$. If thrombolytic therapy is given antithrombotic therapy should not be initiated within $24 \mathrm{~h}$, but Aspirin (160-325 mg loading dose) should be given within the first $48 \mathrm{~h}$ of ischemic stroke. The use of other antiplatelet drug is not accepted in acute stroke.

Early administration of unfractionated heparin, low molecular weight heparin is not recommended.

The European Stroke Organization: guidelines for management of ischemic stroke and transient ischemic attack 2008

Therefore medical systems must have a "fast lane" for patients arriving to the hospital for thrombolysis. The optimal time window for completing diagnostic workup and initiating IV treatment should not exceed $60 \mathrm{~min}$.

The recommended dose of rt-PA used IV is $0.9 \mathrm{mg} / \mathrm{kg}$. A maximum total dose of $90 \mathrm{mg}$ can be given. Ten percent of this must be injected in a bolus. The rest should be administered within the next hour (Table 1). The patient cannot receive antiplatelet or anticoagulant drugs within the first $24 \mathrm{~h}$ if thrombolysis was applied. One day after thrombolysis a cranial CT must be performed to detect intracranial bleed.

\section{ULTRASOUND-ENHANCED INTRAVENOUS THROMBOLYSIS}

Alexandrov (Molina et al., 2004) used a commercially available, $2 \mathrm{MHz}$ transcranial Doppler ultrasound (TCD) to facilitate the effect of rt-PA and to improve revascularization (recanalization) rate during IV thrombolysis for arterial occlusion. Ultrasound (US) enhances the interaction between rt-PA and fibrin. The vibration and the thermal effects improve the breakdown of the clot. The 2-MHz US penetrates through the cranial bone, visualizes the intracranial arteries and measures the direction and speed of the blood flow in the vessels. According to his observations (Alexandrov, 2010a), complete or partial recanalization occurred in $83 \%$ of the US-enhanced thrombolysis cases whereas the rate of recanalization was $50 \%$ when IV thrombolysis was used alone. Symptomatic intracranial bleeding occurred in 3.8\% of both groups. Neurological outcome at 3 months was also better $(51 \%)$ in the US-enhanced group compared to the group with IV thrombolysis alone (37\%).

It is almost a futuristic idea to enhance thrombolysis with both US sonication and micro bubbles. Five micrometer size micro bubbles can be given intraveniously. The microbubbles are destroyed by the US applied through the temporal bone window. This mechanical interaction can further enhance thrombolysis.

In a recent trial 111 patients with acute MCA occlusion were treated with some combination of these interventions. Thirtyeight patients were treated with rt-PA plus continuous $2 \mathrm{~h}$ long TCD monitoring plus galactose-based micro bubbles. The rest of the patients received rt-PA plus continuous $2 \mathrm{~h}$ TCD-US insonation $(N=37)$ or t-PA plus placebo monitoring $(N=36)$. Successful revascularization was seen in $55 \%$ of those patients who received all three interventions (including micro bubbles). The revascularization rate was $41 \%$ for those who received rt-PA and additional TCD sonication therapy, and $24 \%$ for those who underwent rt-PA therapy alone. More than $56 \%$ of the patients receiving combined treatment, including micro bubbles, showed excellent clinical improvement (improved $>4$ points on NIHSS) by 1 day after treatment vs. those receiving rt-PA + TCD-US therapy (41\%) and conventional thrombolysis alone (31\%; Molina et al., 2006). Despite the promising results, sono-thrombolysis is still considered to be an experimental method. The efficacy depends on the presence of the bone window (10-15\% of patients, especially women cannot be effectively sonicated), and the technique is also operator dependent.

\section{INTRAVENOUS THROMBOLYSIS OUTSIDE OF THE TIME WINDOW}

The new MRI techniques (diffusion MRI and the combination of MRI and CT) may help in the selection of patients who might benefit from thrombolysis even after 3 or $4.5 \mathrm{~h}$ after the onset of stroke. (Note: if the diffusion deficit is small and the perfusion deficit is large, a diffusion-perfusion mismatch exists and it might be still worth initiating thrombolysis). Based on such strategy, 72 patients were treated between 3 and $6 \mathrm{~h}$ after the onset of stroke with IV rt-PA in the diffusion-weighted imaging evaluation for understanding stroke evolution (DEFUSE) trial (Olivot et al., 2009). Those patients who had a diffusion-perfusion mismatch benefited from the treatment. Half of the 72 patients enrolled did not have a diffusion-perfusion mismatch and those did not benefit from the thrombolysis. It was also found, that permeability changes detected on MRI can also forecast the appearance of hemorrhagic complications after rt-PA treatment (Kakuda et al., 2008).

Another trial echoplanar imaging thrombolysis evaluation trial (EPITHET), also used perfusion and diffusion MRI to enroll patients for rt-PA treatment 3-6h after stroke. The IV rt-PA decreased the size of irreversibly damaged areas and improved clinical outcome of those patients who had a diffusion-perfusion mismatch on the MRI before the intervention (Davis et al., 2008).

The benefit of extending the period of eligibility for thrombolysis to $9 \mathrm{~h}$ following an acute stroke is being evaluated by the ongoing extending the time for thrombolysis in emergency neurological deficit (EXTEND) ${ }^{1}$ clinical trial, using modern imaging techniques (diffusion, perfusion MRI, perfusion CT; Wintermark et al., 2008).

${ }^{1}$ www.strokecenter.org/trials/TrialDetail.aspx?tid(1059 
Table 2 | Guidelines for the early management of adults with ischemic stroke (AHA/ASA Guideline).

\section{Inclusion criteria}

It is ischemic stroke causing the symptoms

Patients with major deficits should be treated with caution

Thrombolysis may be used in patients with seizures at the time of

presentation when evidence suggests that residual deficits are due to

ischemia rather than the postictal state

Thrombolysis can be initiated within the time window

Patients on anticoagulant therapy with the INR $\leq 1.7$

APTI is in the normal range

\section{Exclusion criteria}

Symptoms are clearing spontaneously

Neurological signs are minor and isolated

Patient had a seizure and has most likely a postictal residual

neurological impairments

Head trauma, stroke, or myocardial infarction in the previous 3 months

Gastrointestinal or urinary tract hemorrhage in previous 21 days

Major surgery in the previous 14 days

Arterial puncture at a non-compressible site in the previous 7 days

History of previous intracranial hemorrhage

Uncontrollable blood pressure over $185 / 110 \mathrm{mmHg}$

Evidence of active bleeding or acute trauma (fracture)

Patients on anticoagulant therapy with the INR $>1.7$

Patient received Heparin in the last $48 \mathrm{~h}$

APTI: over the normal range

Platelet count $<100 \mathrm{G} / \mathrm{L}$

Serum glucose level $<2.7 \mathrm{mmol} / \mathrm{L}(50 \mathrm{mg} / \mathrm{dl})$

Symptoms are suggestive of subarachnoid hemorrhage

CT shows a hypodensity $>1 / 3$ of the cerebral hemisphere

\section{Table 3 | Modified Rankin Scale}

(www.strokecenter.org/trials/scales/rankin).

\begin{tabular}{ll}
\hline Score & Description \\
\hline 0 & No symptoms at all \\
1 & $\begin{array}{l}\text { No significant disability despite symptoms; able to carry out all } \\
\text { usual duties and activities }\end{array}$ \\
2 & $\begin{array}{l}\text { Slight disability; unable to carry out all previous activities, but able } \\
\text { to look after own affairs without assistance }\end{array}$ \\
3 & $\begin{array}{l}\text { Moderate disability; requiring some help, but able to walk without } \\
\text { assistance }\end{array}$ \\
4 & $\begin{array}{l}\text { Moderately severe disability; unable to walk without assistance } \\
\text { and unable to attend to own bodily needs without assistance }\end{array}$ \\
5 & Severe disability; bedridden, incontinent and requiring constant \\
6 & nursing care and attention
\end{tabular}

\section{INTRA-ARTERIAL THROMBOLYSIS}

The following are the theoretical advantages of IA thrombolysis in acute ischemic stroke:

- Fibrinolytic agent can be directly injected into the thrombus

- Revascularization is detected immediately

- Lower dose can be given than in case of IV intervention

- The risk of hemorrhage is lower

The Disadvantages of IA thrombolysis:

- More time is needed for the preparations of the procedure

- Collaboration of interventional radiologists is needed

- Higher costs

- Possibility of arterial injuries
Despite the fact that the IA thrombolysis with rt-PA can be an option for revascularization according to the European Stroke Organization (ESO) $2008^{2}$, and American Heart and Stroke Association (Adams et al., 2007) guidelines, further investigations are recommend to define the appropriate role for this intervention. This is because the recent studies included relatively small number of patients (compared with IV trials) and the optimal dose of IA therapy has not been determined yet (most common dose IA 20-30 mg in $2 \mathrm{~h}$ ). Therefore further trials comparing the efficacy and safety of IV and IA thrombolysis are needed.

A meta-analysis (27 trials, 1117 patients) claimed that the IA thrombolysis increased mortality rates and was associated with worse functional outcome in minor strokes. Furthermore, this meta-analysis suggests that the aggressive IA therapy in mild strokes might result in worse outcomes than the natural course of the disease (Wardlaw et al., 2009).

Recent trials on IA thrombolysis are the following:

In the PROACT I trial (randomized, placebo-controlled) 40 acute stroke patients with MCA occlusion were treated within the first $6 \mathrm{~h}$ of acute stroke with $6 \mathrm{mg}$ pro-urokinase (IA). All patients received IV heparin as well. Recanalization was successful in $57 \%$ of the patients treated with pro-urokinase and in $14 \%$ of the patients treated with placebo $(p=0.017)$. Bleeding or clinical decline occurred in $15 \%$ of the pro-urokinase and in $7 \%$ of the placebo-treated patients (del Zoppo et al., 1998).

The subsequent PROACT II, a multicenter, randomized trial, trial examined the effect of IA recombinant pro-urokinase on MCA revascularization with treatment applied within the first $6 \mathrm{~h}$ of stroke (Furlan et al., 1999). There were 180 patients who received heparin or heparin $+9 \mathrm{mg}$ IA pro-urokinase (slow IA

\footnotetext{
${ }^{2}$ www.eso-stroke.org/pdf/ESO\%20Guidelines_update_Jan_2009.pdf
} 
infusion under $2 \mathrm{~h}$; max. dose was given in each case regardless of early recanalization). This study showed a $66 \%$ recanalization rate in the pro-urokinase and $18 \%$ in the control group. The non-disabling (0-2 point on the modified Rankin Scale) 3-month functional outcome was significantly better if pro-urokinase was used compared to placebo (improvement: 40 vs. $25 \%, p=0.04$ ). Intracerebral hemorrhage with neurological deterioration within $24 \mathrm{~h}$ occurred in $10.9 \%$ of the pro-urokinase group and $3.1 \%$ of the controls. Death rates were similar in both groups. This trial proved the efficacy of pro-urokinase used within the first $6 \mathrm{~h}$ of acute stroke in case of MCA occlusion. The results were compared to the results of the NINDS trial. The 3-month outcome was better than in the placebo-arm of the NINDS trial. The 3-month mortality rates were lower in the PROACT II trial (16\%) compared to the placebo $(24 \%)$ and the rt-PA treated (21\%) group of the NINDS trial (The National Institute of Neurological Disorders and Stroke rt-PA Stroke Study Group, 1995).

Another IA urokinase (given in 120,000 IU boluses, total dose of $600,000 \mathrm{IU}$ within the first $6 \mathrm{~h}$ of acute stroke) trial the socalled MCA-embolism local fibrinolytic intervention trial (MELT) was performed in Japan. Partial or complete recanalization was achieved in $74 \%$ of the subjects treated with urokinase. Favorable 3 month outcomes, both non-disabling (0-2 points on the modified Rankin Scale) and excellent (0-1 point on the modified Rankin Scale), were more common in the urokinase group compared to the control group ( 49.1 vs. $38.6 \%$ and 42.1 vs. $22.8 \%$, $p=0.045)$. Three-month mortality rates $(5.3 \%$ in the urokinase and $3.5 \%$ in the control group, $p=1.00$ ) and the rate of symptomatic intracerebral bleedings (9\% in the urokinase and $2 \%$ in the control group, $p=0.206$ ) did not differ significantly from the control group. Since rt-PA was just approved in Japan during that period, the MELT trial was stopped after the enrollment of 114 patients (Ogawa et al., 2007).

A recent meta-analysis (PROACT, PROACT II, and MELT) showed that IA thrombolysis resulted in better 3-month clinical outcomes. Although partial or complete recanalization was achieved in a high proportion of subjects (74\% in MELT and 66\% in PROACT II), the rate of complete recanalization was low $(5 \%$ in MELT, $18 \%$ in the treated arm of PROACT II; Saver, 2007).

\section{COMBINED (INTRAVENOUS + INTRA-ARTERIAL) THROMBOLYSIS}

This procedure should begin with the IV thrombolysis and should proceed to IA therapy only if the first intervention fails to accomplish revascularization. If the IA procedure also fails, the pharmacological procedure may be complemented with a mechanical thrombectomy.

The emergency management of stroke (EMS) trial compared the efficacy of combined (IV + IA) thrombolysis with IA thrombolysis alone started within the first $3 \mathrm{~h}$ of stroke (enrolled 35 patients). The results showed higher recanalization rates with combined (IV + IA) thrombolysis, but no difference between the two groups in the clinical improvement. Hemorrhagic transformation was seen more often if combined therapy was used (Lewandowski et al., 1999).
In the interventional management of stroke (IMS) trial patients with arterial occlusion, confirmed by angiography, were treated within the first $3 \mathrm{~h}$ of stroke with $0.6 \mathrm{mg} / \mathrm{kg}$ rt-PA IV. If needed, the IV treatment was complemented with IA rt-PA (max. $22 \mathrm{mg} / 2 \mathrm{~h}$ directly into the thrombus) treatment. Results were compared to primary results of placebo or IV rt-PA therapy from the NINDS trial. The 3-month mortality in IMS subjects (16\%) was lower but not statistically different than the mortality of placebo $(24 \%)$ and rt-PA-treated subjects $(21 \%)$ in the NINDS rt-PA stroke trial. The rate of symptomatic intracerebral hemorrhage $(6.3 \%)$ in IMS subjects was similar to that of rt-PA-treated subjects $(6.6 \%)$ but higher than the rate in placebo-treated subjects $(1.0 \%, p=0.018)$. The rates of intracerebral hemorrhage were similar in all groups but IMS subjects had a significantly better outcome at 3 months than NINDS placebo-treated subjects (IMS Study Investigators, 2004).

The IMS-II trial found combined thrombolysis (IV + IA) to be more beneficial in acute stroke patients. Additional US therapy was also used in this trial to dissolve the thrombus (IMS II Trial Investigators, 2007; Tomsick et al., 2008). The trial involved relatively few patients. Out of $73 \mathrm{IV}(0.6 \mathrm{mg} / \mathrm{kg}$ over $30 \mathrm{~min})$ treated patients 50 received additional IA thrombolysis (max. $22 \mathrm{mg}$ IA) and 34 underwent low energy US therapy as well. The mortality rate was $16 \%$ and the rate of intracranial hemorrhage was $9.9 \%$ in the IMS-II subjects. Patients undergoing combined thrombolysis showed significantly better outcome than the placebo group, and better outcome than the rt-PA treated group of the NINDS trial did.

\section{MECHANICAL THROMBECTOMY}

The IV thrombolysis does not always result in revascularization and clinical improvement. The success rates of the IV rt-PA treatment, based on anatomical location, are the following:

- Basilar artery: $30 \%$

- Terminal part of the ICA: $6 \%$

- M1 part of the MCA: $30 \%$

- M2 part of the MCA: $44 \%$

- Tandem ICA and MCA occlusion: 27\% (Alexandrov, 2010b)

The failure of therapy can not solely be explained by the size of the thrombus. The composition of the thrombus also plays a role, because an arteriosclerotic plaque cannot be dissolved either by rt-PA or by any other thrombolytic drug. Pharmacological thrombolysis is more effective in case of distal occlusions (e.g., small branches of the MCA), while mechanical devices are more useful in proximal main stem occlusions. The mechanical embolus removal in cerebral ischemia (MERCI) technique and device removes the embolus from the blood vessel, like a corkscrew.

Mechanical embolectomy can be beneficial if:

- the patient is excluded from the pharmacological thrombolysis (e.g., after surgery)

- pharmacological thrombolysis did not lead to recanalization

- the patient suffers from coagulopathy

- the thrombus is calcified

- beyond the 3-h time window 


\section{Disadvantages of MERCI:}

- difficult to reach the thrombus in sclerotic arteries

- dissection or perforation of the vessels can occur

- the thrombus might break into parts and cause distal occlusion

Mechanical embolus removal in cerebral ischemia was the first device approved by FDA in 2004. Since then more than 10,000 devices are in use worldwide, and many variants have been produced. The principle behind this intervention is that a MERCI micro-catheter (thin metal spiral) goes through the thrombus, a balloon is blown up distally from the thrombus and the device removes the blood clot. The balloon is used for preventing distal embolization (Alexandrov, 2010b).

In the MERCI-I trial 28 patients were treated with this technique. Sixty-four percent of the patients had successful recanalization and nine $(32 \%)$ out of the recanalized patients showed significant clinical improvement, reaching $0-2$ points on the modified Rankin Scale. In the MERCI-II trial partial or complete recanalization was achieved in approximately half (48\%) of the 141 treated patients. Clinically significant procedural complications occurred in $10(7 \%)$ patients. Clinically symptomatic intracranial bleeding occurred in $7.8 \%$ of the patients. Patients undergoing successful recanalization showed significantly better improvement reaching 0-2 scores on the modified Rankin Scale at the 3-month follow-up. The clinical improvement was $46 \%$ if recanalization was successful and only $10 \%$ if recanalization failed $(p=0.001)$. Mortality rates were better if recanalization was successful compared to those when recanalization failed (32 vs. 54\%; Smith et al., 2008a).

Mechanical embolus removal in cerebral ischemia showed to be particularly effective in case of main stem occlusions. Fiftythree percent recanalization rate was achieved with MERCI for internal carotid occlusions and 39\% of these cases showed good clinical outcome (reaching 0-2 scores on the modified Rankin Scale). In the cases of internal carotid occlusion of those patients who failed the MERCI revascularization procedure only 3\% had favorable outcome. Mortality rate was $30 \%$ in the group with successful recanalization and $73 \%$ in the ICA group without successful recanalization.

In the Multi-MERCI trial if recanalization failed in response to the IV rt-PA treatment mechanical thrombectomy was applied (131 patients). Recanalization was successful in 75 of 131 $(57.3 \%)$ cases. Additional methods (IA thrombolysis) increased the recanalization rate to approximately $70 \%$. Favorable clinical outcomes (0-2 points at the modified Rankin Scale) occurred in $36 \%$ and mortality was $34 \%$; both outcomes were significantly related to vascular recanalization. Symptomatic intracerebral hemorrhage occurred in 16 patients $(9.8 \%)$. Clinically significant procedural complications occurred in nine (5.5\%) patients (Flint et al., 2007; Smith et al., 2008a,b; Nogueira et al., 2009; Shi et al., 2010).

The so-called Penumbra aspiration device was approved by FDA in 2008. It consists of four micro-catheters, with different sizes, according to the size of different arteries. The device destructs and aspirates the thrombus. Two trials have already proved the effectiveness of the Penumbra device when used within the first
$8 \mathrm{~h}$ of acute stroke, in case of patients who score higher than eight points on the NIHSS (Penumbra Pivotal Stroke Trial Investigators, 2009). The Penumbra device achieved recanalization in $80 \%$ of the 125 patients and $25 \%$ of the patients had $0-2$ points on the modified Rankin Scale 3 months after the procedure. The rate of symptomatic intracerebral bleedings was $2 \%$ and the 3 -month mortality rate was $30 \%$. While the "corkscrew" devices, like MERCI go through the thrombus, most of the aspiration devices, like Penumbra, are applied proximal to the thrombus; this decreases the risk of embolization.

Many other devices have been developed so far. One of them is the Catch Thromb-embolectomy System, which is a "basket-like" $4 \mathrm{~mm}$ equipment. The Phenox blood clot remover acts like a brush on a flexible wire, containing brush-microfilaments. All these attempts prove that there is no universal device able to remove all types of thrombus. Furthermore, a successful recanalization does not always automatically result in obvious clinical improvement. However, the analysis of more than 1000 acute stroke cases (33 trials) confirmed that mechanical recanalization increases the chance of good outcome.

Mechanical devices have several key advantages:

- recanalization occurs in approximately half of the treated patients (confirmed by angiography)

- recanalization occurs without the disruption of blood-brain barrier

- no neurotoxicity (e.g., rt-PA is neurotoxic).

There are, however, some disadvantages to these techniques:

- they require an experienced interventional neuro-radiologist

- the devices are expensive

- they increase the risk of bleeding during the procedure.

Ongoing randomized trials (Khatri et al., 2008) are expected to better define the role of these mechanical devices in the management of acute ischemic stroke magnetic resonance and recanalization of stroke clot using embolectomy (MR-RESCUE) and IMS-III.

At this moment, pharmacological and mechanical stroke treatment strategies are considered to be complementary.

\section{STENTING IN ACUTE ISCHEMIC STROKE}

There are only few studies investigating the utility of intracranial stents for the treatment of acute ICA occlusion. An FDA trial, including 20 patients reported the effectiveness and safety of this procedure used in the first $8 \mathrm{~h}$ of acute stroke. Recanalization was successful in half of the patients. There was one symptomatic and two asymptomatic intracranial hemorrhages. One month after the procedure nine patients (45\%) scored $<1$ and $60 \%$ of the patients scored $<3$ on the modified Rankin Scale (Levy et al., 2009). In acute stenting it is difficult to pass through the atherosclerotic carotid bifurcation. The concomitant antiplatelet therapy increases the risk of hemorrhagic transformation or the risk of bleeding caused by reperfusion. In a study of 25 patients 23 were successfully recanalized. One bleeding and one carotid dissection occurred. No data are available regarding the clinical outcomes (Jovin et al., 2005). 
TRIALS COMBINING PHARMACOLOGICAL THROMBOLYSIS WITH MECHANICAL RECANALIZATION DEVICES

The ongoing IMS-III trial is investigating whether a combined IV and IA thrombolysis is superior to standard IV (standard dose of $0.9 \mathrm{mg} / \mathrm{kg}$ ) rt-PA therapy alone if it is initiated within the first $3 \mathrm{~h}$ of acute stroke. The combined IV/IA group will receive a lower dose of rt-PA ( $0.6 \mathrm{mg} / \mathrm{kg}, 60 \mathrm{mg}$ max.) over $40 \mathrm{~min}$ followed by immediate angiography. If the thrombus is resolved, no additional IA therapy is administered. If the occlusion is still present, the thrombolysis will be completed by IA treatment (max. dose of $22 \mathrm{mg}$ of rt-PA). The IA treatment must be started within the first $5 \mathrm{~h}$ and must be completed within the end of the seventh hour of the acute stroke. IA thrombolysis might be combined with low-intensity US and thrombus-removal device as well. The clinical outcome is calculated by the modified Rankin Scale 3 months after the procedure (Khatri et al., 2008).

The ongoing MR-RESCUE trial is evaluating the efficacy of the standard medical thrombolysis in case of proximal main branch occlusion in the anterior circulation compared to the efficacy of mechanical thrombectomy (either with MERCI or Penumbra, in the first $8 \mathrm{~h}$ of acute stroke).

Those patients who arrive in the first $4.5 \mathrm{~h}$ of stroke might undergo standard IV thrombolysis before the mechanical thrombectomy. The outcome is evaluated with modified Rankin Scale 3 months after stroke ${ }^{3}$.

The DAWN trial (DWI/PWI and CTP assessment in the triage of wake-up and late presenting strokes undergoing neurointervention) selects patients according to the MRI or CT perfusion images more than $8 \mathrm{~h}$ after the onset of stroke. Patients with witnessed or non-witnessed (including wake-up) strokes with "last time seen well" between 7 and $23 \mathrm{~h}$, having a large arterial occlusion in the anterior circulation are selected. The treatment is initiated between 8 and $24 \mathrm{~h}$. Results will be evaluated by the modified Rankin Scale 3 months after stroke ${ }^{4}$.

\section{IMPROVING PERFUSION BY MODULATING GLOBAL REPERFUSION OR BY TRANS-ARTERIAL RETROGRADE REPERFUSION TECHNIOUE}

The principle behind this strategy is to increase blood flow through the lepto-meningeal arteries or through the collaterals of the circle of Willis. This can be accomplished by pharmacological (IV phenyl-epinephrine infusion) therapy or by a mechanical device. The safety and efficacy of neuroflo ${ }^{\mathrm{TM}}$ technology in ischemic stroke (SENTIS) trial randomized subjects within the first $14 \mathrm{~h}$ of acute stroke. They tried to achieve beneficial outcome by inserting an intra-aortic balloon under the region of the renal arteries to increase intracerebral blood flow through the collaterals. The results were compared to conventional medical therapy alone ${ }^{5}$. Enrollment was completed in 2010, but only preliminary data from 2008 are available at the moment: adverse events (fatal and non-fatal) were found to appear equally (34\%) in both the control and the treated groups. However, mortality was significantly

\footnotetext{
${ }^{3}$ www.strokecenter.org/trials/TrialDetail.aspx?tid(559

${ }^{4}$ www.strokecenter.org/trials/TrialDetail.aspx?tid(960

${ }^{5}$ www.strokecenter.org/trials/TrialDetail.aspx?tid(618
}

lower for the treated population $(6.4 \%)$ vs. the control population (14.9\%), with more stroke progression (8.5\%) and hemorrhagic transformation of the stroke area $(4.3 \%)$ in the control population (Uflacker et al., 2008).

\section{NEUROPROTECTION}

There are more than 100 medications that reached clinical phase after they have been proven to be effective in animal models. None of them has proved to be effective in human trials yet. Neuroprotectants would have the most clinical utility if they could be used for both ischemic and hemorrhagic strokes early at the scene by the paramedics (Danton and Dietrich, 2004).

\section{"OPTIMAL" STROKE MANAGEMENT}

The success of recanalization does not only depend on the efficacy of the thrombolysis or the mechanical thrombectomy but also on the organization of the stroke units. All elements of the "chain of stroke management" must be appropriately controlled in order to increase the number of patients who are suitable for recanalization therapy. The elements are the following: does the patient recognize the symptoms of stroke? - Does the patient know about the time window? - Do stroke patients have priority transport with advanced notification to the hospital? - Are pre- and in-hospital pathways well organized? - Does the hospital have a stroke unit?

Why are stroke units special? International, multicenter, randomized clinical trials have proven that treatment provided in stroke units decreases the risk of death and severe disability by minimum 25\% (Stroke Unit Trialists' Collaboration, 2000). The Cochrane analyses confirmed that patients treated in stroke units (independent of age, gender, or stroke type) have a significantly better chance to be alive 1 year after the stroke and to live at home instead of becoming severely disabled compared to patients who

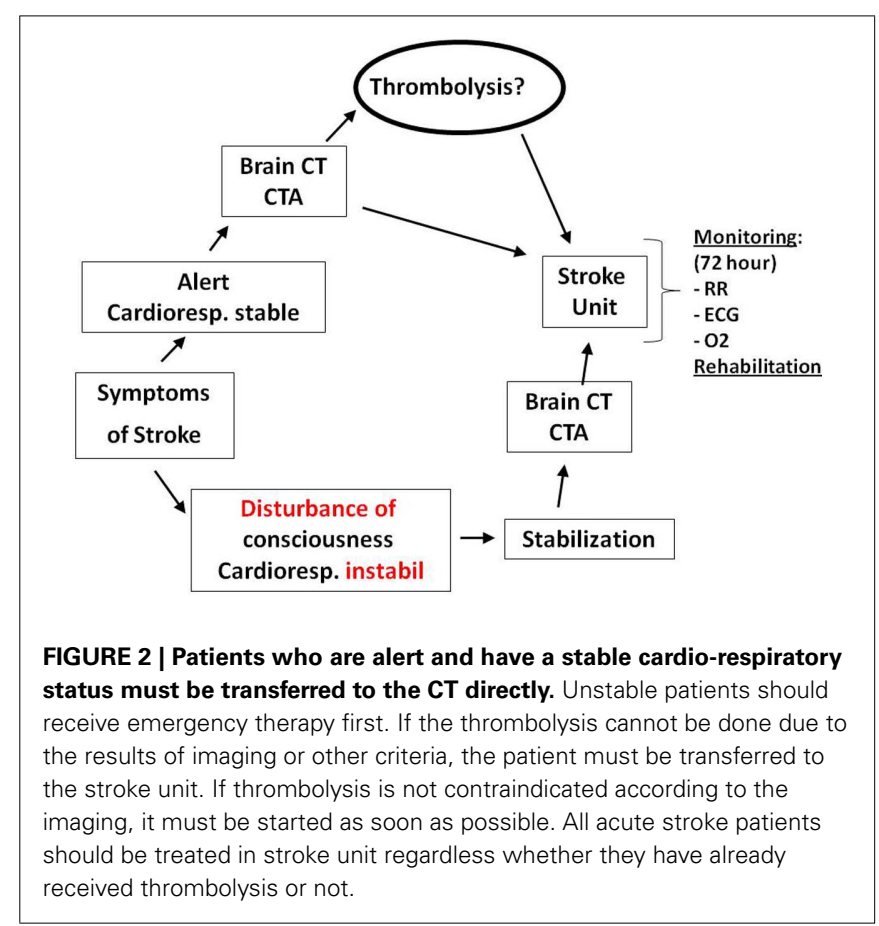




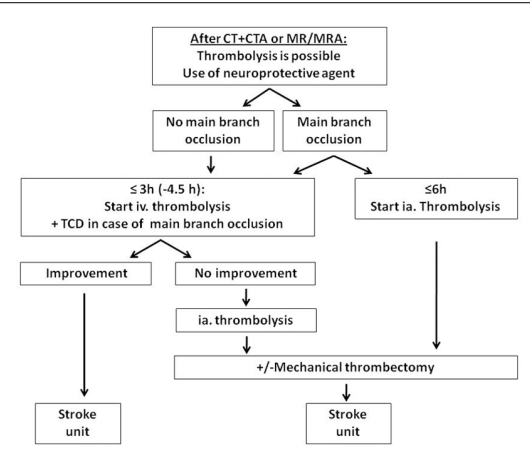

FIGURE 3 | The future of acute stroke therapy. A neuroprotective drug is administered on the site (not yet available).

were not treated in such stroke units. The most important elements of stroke units are (Alberts et al., 2005):

- experienced physicians, nurses, and physiotherapists, who are familiar with stroke management

- monitoring for cardio-respiratory status

- protocolized stroke management

- integrated emergency system and well organized in-hospital management

- laboratory and CT available around the clock

A personal "vision" about the future of stroke management:

- "Mobile CT" could differentiate ischemic strokes from hemorrhagic ones at the scene

\section{REFERENCES}

Adams, H. P. Jr., del Zoppo, G., Alberts, M. J., Bhatt, D. L., Brass, L., Furlan, A., Grubb, R. L., Higashida, R. T., Jauch, E. C., Kidwell, C., Lyden, P. D., Morgenstern, L. B., Qureshi, A. I., Rosenwasser, R. H., Scott, P. A., Wijdicks, E. F., and American Heart Association/American Stroke Association Stroke Council, American Heart Association/American Stroke Association Clinical Cardiology Council, American Heart Association/American Stroke Association Cardiovascular Radiology and Intervention Council, Atherosclerotic Peripheral Vascular Disease Working Group, Quality of Care Outcomes in Research Interdisciplinary Working Group. (2007). Guidelines for the early management of adults with ischemic stroke: a guideline from the American Heart Association/American Stroke Association Stroke Council, Clinical Cardiology Council, Cardiovascular Radiology and Intervention Council, and the Atherosclerotic Peripheral Vascular Disease and Quality of Care Outcomes in Research Interdisciplinary Working Groups: the American Academy of Neurology affirms the value of this guideline as an educational tool for neurologists. Circulation 115, e478-e534.

Alberts, M. J., Latchaw, R. E., Selman, W. R., Shephard, T., Hadley, M. N., Brass, L. M., Koroshetz, W., Marler, J. R., Booss, J., Zorowitz, R. D., Croft, J. B., Magnis, E., Mulligan, D., Jagoda, A., O'Connor, R., Cawley, C. M., Connors, J. J., Rose-DeRenzy, J. A., Emr, M., Warren, M., and Walker, M. D. (2005). Recommendations for comprehensive stroke centers: a consensus statement from the Brain Attack Coalition. Stroke 36, 1597-1616.

Alexandrov, A. V. (2010a). Ultrasound enhanced thrombolysis for stroke. $J$. Int. Med. 267, 209-219.

Alexandrov, A. V. (2010b). Current and future recanalisation strategies for acute ischemic stroke (Review). J. Intern. Med. 267, 209-219.

Astrup, J., Siesjö, B. K., and Symon, L. (1981). Thresholds in cerebral

- Neuroprotective agents (with proven effect both in ischemic and hemorrhagic stroke) could be given by paramedics before arrival to the stroke unit

- Alert patients with stable cardio-respiratory status should be transferred directly to the CT. The neurological examination and blood sampling should be performed at the radiology (CT) area to save time (Figure 2)

- Within the 3 or 4.5 -h time window thrombolysis should be started IV in case of large vessel occlusion (both large vessel and MCA branch), but the interventional team should also prepare for the possible IA mechanical bridging therapy. Therefore, if the IV procedure fails to result in clinical improvement, the neurologist may individually decide on continuing the thrombolysis IA or on applying a mechanical removal device. All of these methods might be combined (Figure 3)

- Patients both with IV or IA thrombolysis must be observed at an intensive care unit for $72 \mathrm{~h}$ regardless of the success of recanalization

- Rehabilitation must already be started at the stroke unit and should be continued at the rehabilitation department/hospital.

\section{SUMMARY}

Successful acute stroke therapy can only be achieved by well organized patient pathways. The success depends on the early recognition of the alarming symptoms, on well/organized preand in-hospital patient management, on the individual decisions over the therapeutic modality, on the detailed monitoring in the stroke units and on efficient rehabilitation. Every component must be well organized, because the strength of the chain is determined by the weakest element.

ischemia - the ischemic penumbra. Stroke 12, 723-725.

Cornu, C., Amsallem, E., and SerradjJaillard, A. A. (2001). Thrombolytic therapy for acute ischemic stroke. Am. J. Cardiovasc. Drugs 4, 281-292.

Csiba, L., Paschen, W., and Hossmann, K. A. (1983). A topographic quantitative method for measuring brain tissue $\mathrm{pH}$ under physiological and pathophysiological conditions. Brain Res. 289, 334-337.

Csiba, L., Paschen, W., and Mies, G. (1985). Regional changes in tissue $\mathrm{pH}$ and glucose content during cortical spreading depression in rat brain. Brain Res. 336, 167-170.

Danton, G. H., and Dietrich, W. D. (2004). The search for neuroprotective strategies in stroke. AJNR Am. J. Neuroradiol. 25, 181-194.

Davis, S. M., Donnan, G. A., Parsons, M. W., Levi, C., Butcher, K. S., Peeters, A., Barber, P. A., Bladin, C., De Silva, D. A., Byrnes, G., Chalk, J. B., Fink, J. N., Kimber, T.
E., Schultz, D., Hand, P. J., Frayne, J., Hankey, G., Muir, K., Gerraty, R., Tress, B. M., Desmond, P. M., and EPITHET investigators. (2008). Effects of alteplase beyond $3 \mathrm{~h}$ after stroke in the echoplanar imaging thrombolytic evaluation trial (EPITHET): a placebo-controlled randomised trial. Lancet Neurol. 7, 299-309.

delZoppo, G. J., Higashida, R. T., Furlan, A. J., Pessin, M. S., Rowley, H. A., and Gent, M. (1998). PROACT: a phase II randomized trial of recombinant pro-urokinase by direct arterial delivery in acute middle cerebral artery stroke. PROACT investigators. Prolyse in acute cerebral thromboembolism. Stroke 29, 4-11.

Flint, A. C., Duckwiler, G. R., Budzik, R. F., Liebeskind, D. S., Smith, W. S., and MERCI and Multi MERCI Writing Committee. (2007). Mechanical thrombectomy of intracranial internal carotid occlusion: pooled results of the MERCI and multi MERCI part I trials. Stroke 38, 1274-1280. 
Furlan, A., Higashida, R., Wechsler, L., Gent, M., Rowley, H., Kase, C., Pessin, M., Ahuja, A., Callahan, F., Clark, W. M., Silver, F., and Rivera, F. (1999). Intra-arterial prourokinase for acute ischemic stroke. The PROACT II study: a randomized controlled trial. Prolyse in acute cerebral thromboembolism. JAMA 282, 2003-2011.

Furlan, A. J., and Abou-Chebl, A. (2002). The role of recombinant pro-urokinase (r-pro-UK) and intra-arterial thrombolysis in acute ischaemic stroke: the PROACT trials. Prolyse in acute cerebral thromboembolism. Curr. Med. Res. Opin. 18(Suppl. 2), s44-s47.

Hacke, W., Albers, G., Al-Rawi, Y., Bogousslavsky, J., Davalos, A., Eliasziw, M., Fischer, M., Furlan, A., Kaste, M., Lees, K. R., Soehngen, M., Warach, S., and DIAS Study Group. (2005). The desmoteplase in acute ischemic stroke trial (DIAS): a phase II MRI-based 9-hour window acute stroke thrombolysis trial with intravenous desmoteplase. Stroke 36, 66-73.

Haley, E. C. Jr., Lyden, P. D., Johnston, K. C., Hemmen, T. M., and TNK in Stroke Investigators. (2005). A pilot dose-escalation safety study of tenecteplase in acute ischemic stroke. Stroke 36, 607-612.

IMS Study Investigators. (2004). Combined intravenous and intra-arterial recanalisation for acute ischemic stroke: the Interventional Management of Stroke Study. Stroke 35, 904-911.

IMS II Trial Investigators. (2007). The Interventional Management of Stroke (IMS) II Study. Stroke 38, 2127-2135.

Jovin, T. G., Gupta, R., Uchino, K., Jungreis, C. A., Wechsler, L. R., Hammer, M. D., Tayal, A., and Horowitz, M. B. (2005). Emergent stenting of extracranial internal carotid artery occlusion in acute stroke has a high revascularization rate. Stroke 36, 2426-2430.

Kakuda, W., Lansberg, M. G., Thijs, V. N., Kemp, S. M., Bammer, R., Wechsler, L. R., Moseley, M. E., Marks, M. P., Albers, G. W., and DEFUSE Investigators. (2008). Optimal definition for PWI/DWI mismatch in acute ischemic stroke patients. J. Cereb. Blood Flow Metab. 28, 887-891.

Khatri, P., Hill, M. D., Palesch, Y. Y., Spilker, J., Jauch, E. C., Carrozzella, J. A., Demchuk, A. M., Martin, R., Mauldin, P., Dillon, C., Ryckborst, K. J., Janis, S., Tomsick, T. A., Broderick, J. P., and Interventional Management of Stroke III Investigators.
(2008). Methodology of the Interventional Management of Stroke III Trial. Int. J. Stroke 3, 130-137.

Kuroiwa, T., Miyasaka, N., Fengyo, Z., Yamada, I., Nakane, M., Nagaoka, T., Tamura, A., Ohno, K. (2007). Experimental ischemic brain edema: morphological and magnetic resonance imaging findings. Neurosurg. Focus 22, E11.

Kwiatkowski, T. G., Libman, R. B., Frankel, M., Tilley, B. C., Morgenstern, L. B., Lu, M., Broderick, J. P., Lewandowski, C. A., Marler, J. R., Levine, S. R., and Brott, T. (1999). Effects of tissue plasminogen activator for acute ischemic stroke at one year. National Institute of Neurological Disorders and Stroke Recombinant Tissue Plasminogen Activator Stroke Study Group. N. Engl. J. Med. 340, 1781-1787.

Levy, E. I., Siddiqui, A. H., Crumlish, A., Snyder, K. V., Hauck, E. F., Fiorella, D. J., Hopkins, L. N., and Mocco, J. (2009). First Food and Drug Administration-approved prospective trial of primary intracranial stenting for acute stroke: SARIS (stent-assisted recanalization in acute ischemic stroke). Stroke 40, 3552-3556.

Lewandowski, C. A., Frankel, M., Tomsick, T. A., Broderick, J., Frey, J., Clark, W., Starkman, S., Grotta, J., Spilker, J., Khoury, J., and Brott, T. (1999). Combined intravenous and intra-arterial $r$-TPA versus intraarterial therapy of acute ischemic stroke: emergency management of stroke (EMS) bridging trial. Stroke 30, 2598-2605.

Liebeskind, D. S. (2009). Reversing stroke in the 2010s: lessons from desmoteplase in acute ischemic stroke-2 (DIAS-2). Stroke 40, 3156-3158.

Marler, J. R., Tilley, B. C., and Lu, M., Brott, T. G., Lyden, P. C., Grotta, J. C., Broderick, J. P., Levine, S. R., Frankel, M. P., Horowitz, S. H., Haley, E. C. Jr., Lewandowski, C. A., and Kwiatkowski, T. P. (2000). Early stroke treatment associated with better outcome: the NINDS rt-PA stroke study. Neurology 55, 1649-1655.

Micieli, G., Marcheselli, S., and Tosi, P. (2009). Safety and efficacy of alteplase in the treatment of acute ischemic stroke. Vasc. Health Risk Manag. 5, 397-409.

Molina, C. A., Grotta, J. C., Garami, Z., Ford, S. R., Alvarez-Sabin, J., Montaner, J., Saqqur, M., Demchuk, A. M., Moyé, L. A., Hill, M. D., Wojner, A. W., CLOTBUST Investigators. (2004).
Ultrasound-enhanced systemic thrombolysis for acute ischemic stroke. N. Engl. J. Med. 351, 2170-2178.

Molina, C. A., Ribo, M., Rubiera, M., Montaner, J., Santamarina, E., Delgado-Mederos, R., Arenillas, J. F., Huertas, R., Purroy, F., Delgado, P., and Alvarez-Sabín, J. (2006). Microbubble administration accelerates clot lysis during continuous $2-\mathrm{MHz}$ ultrasound monitoring in stroke patients treated with intravenous tissue plasminogen activator. Stroke 37, 425-429.

Murray, V., Norrving, B., Sandercock, P. A. G., Terént, A., Wardlaw, J. M., and Wester, P. (2010). The molecular basis of thrombolysis and its clinical application in stroke. J. Intern. Med. 267, 191-208.

Nogueira, R. G., Liebeskind, D. S., Sung, G., Duckwiler, G., and Smith, W. S. (2009). MERCI; Multi MERCI Writing Committee. Predictors of good clinical outcomes, mortality, and successful revascularization in patients with acute ischemic stroke undergoing thrombectomy: pooled analysis of the mechanical embolus removal in cerebral ischemia (MERCI) and Multi MERCI Trials. Stroke 40, 3777-3783.

Ogawa, A., Mori, E., Minematsu, K. Taki, W., Takahashi, A., Nemoto, S., Miyamoto, S., Sasaki, M., Inoue, T., and MELT Japan Study Group. (2007). Randomized trial of intraarterial infusion of urokinase within 6 hours of middle cerebral artery stroke: the middle cerebral artery embolism local fibrinolytic intervention trial (MELT) Japan. Stroke 38, 2633-2639.

Olivot, J. M., Mlynash, M., Thijs, V. N., Purushotham, A., Kemp, S., Lansberg, M. G., Wechsler, L., Gold, G. E., Bammer, R., Marks, M. P., and Albers, G. W. (2009). Geography, structure, and evolution of diffusion and perfusion lesions in diffusion and perfusion imaging evaluation for understanding stroke evolution (DEFUSE). Stroke 40, 3245-3251.

Paciaroni, M., Medeiros, E., and Bogousslavsky, J. (2009). Desmoteplase. Expert Opin. Biol. Ther. 9, 773-778.

Parsons, M. W., Miteff, F., Bateman, G. A., Spratt, N., Loiselle, A. Attia, J., and Levi, C. R. (2009). Acute ischemic stroke: imagingguided tenecteplase treatment in an extended time window. Neurology 72, 915-921.

Penumbra Pivotal Stroke Trial Investigators. (2009). The penumbra pivotal stroke trial: safety and effectiveness of a new generation of mechanical devices for clot removal in intracranial large vessel occlusive disease. Stroke 40, 2761-2768.

Qureshi, A. I., Harris-Lane, P., Kirmani, J. F., Janjua, N., Divani, A. A., Mohammad, Y. M., Suarez, J. I., and Montgomery, M. O. (2006). Intra-arterial reteplase and intravenous abciximab in patients with acute ischemic stroke: an open-label, dose-ranging, phase I study. Neurosurgery 59, 789-796; discussion 796-797.

Qureshi, A. I., Pande, R. U., Kim, S. H., Hanel, R. A., Kirmani, J. F., and Yahia, A. M. (2002). Third generation thrombolytics for the treatment of ischemic stroke. Curr. Opin. Investig. Drugs 3, 1729-1732.

Saver, J. F. (2006). Time is brain!quantified. Stroke 37, 263-266.

Saver, J. L. (2004). Number needed to treat estimates incorporating effects over the entire range of clinical outcomes: novel derivation method and application to thrombolytic therapy for acute stroke. Arch. Neurol. 61, 1066-1067.

Saver, J. L. (2007). Intra-arterial fibrinolysis for acute ischemic stroke: the message of MELT. Stroke 38, 2627-2628.

Saver, J. L., Gornbein, J., Grotta, J., Liebeskind, D., Lutsep, H., Schwamm, L., Scott, P., and Starkman, S. (2009). Number needed to treat to benefit and to harm for intravenous tissue plasminogen activator therapy in the 3- to 4.5-hour window: joint outcome table analysis of the ECASS 3 trial. Stroke 40, 2433-2437.

Saver, J. L., Smith, E. E., Fonarow, G. C., Reeves, M. J., Zhao, X., Olson, D. M., Schwamm, L. H., and on behalf of the GWTG-Stroke Steering Committee. (2010). The "golden hour" and acute brain ischemia: presenting features and lytic therapy in $>30,000$ patients arriving within 60 minutes of stroke onset stroke. Stroke 41, 1431-1439.

Segura, T., Calleja, S., and Jordan, J. (2008). Recommendations and treatment strategies for the management of acute ischemic stroke. Expert Opin. Pharmacother. 9, 1071-1085.

Shi, Z. S., Loh, Y., Walker, G., and Duckwiler, G. R. (2010). Clinical outcomes in middle cerebral artery trunk occlusions versus secondary division occlusions after mechanical thrombectomy: pooled analysis of the mechanical embolus removal in cerebral ischemia (MERCI) and multi MERCI trials. Stroke 41, 953-960. 
Smith, W. S., Sung, G., Starkman, S., Saver, J. L., Kidwell, C. S., Gobin, Y. P., Lutsep, H. L., Nesbit, G. M., Grobelny, T., Rymer, M. M., Silverman, I. E., Higashida, R. T., Budzik, R. F., Marks, M. P., and MERCI Trial Investigators. (2008a). Safety and efficacy of mechanical embolectomy in acute stroke: results of the MERCI trial. Stroke 39, 1205-1212.

Smith, W. S., Sung, G., Saver, J., Budzik, R., Duckwiler, G., Liebeskind, D. S., Lutsep, H. L., Rymer, M. M., Higashida, R. T., Starkman, S., Gobin, Y. P., Multi MERCI Investigators, Frei, D., Grobelny, T., Hellinger, F., Huddle, D., Kidwell, C., Koroshetz, W., Marks, M., Nesbit, G., and Silverman, I. E. (2008b). Mechanical thrombectomy for acute ischemic stroke: final results of the multi MERCI trial. Stroke 39, 1205-1212.

Stroke Unit Trialists' Collaboration. (2007). Organised inpatient (stroke unit) care for stroke. Cochrane Database Syst. Rev. CD000197.

The National Institute of Neurological Disorders and Stroke rt-PA Stroke Study Group. (1995). Tissue plasminogen activator for acute ischemic stroke. N. Engl. J. Med. 333, 1581-1587.

Tomsick, T., Broderick, J., Carrozella, J., Khatri, P., Hill, M., Palesch, Y., Khoury, J., and Interventional Management of Stroke II Investigators. (2008). Revascularization results in the Interventional Management of Stroke II trial. AJNR Am. J. Neuroradiol. 29, 582-587.

Uflacker, R., Schönholz, C., Papamitisakis, N., and SENTIS trial. (2008). Interim report of the SENTIS trial: cerebral perfusion augmentation via partial aortic occlusion in acute ischemic stroke. J. Cardiovasc. Surg. (Torino) 49, 715-721.
Wardlaw, J. M., Murray, V., Berge, E., and Del Zoppo, G. J. (2009). Thrombolysis for acute ischaemic stroke. Cochrane Database Syst. Rev. CD000213.

Wintermark, M., Albers, G. W., Alexandrov, A. V., Alger, J. R., Bammer, R., Baron, J. C., Davis, S., Demaerschalk, B. M., Derdeyn, C. P., Donnan, G. A., Eastwood, J. D., Fiebach, J. B., Fisher, M., Furie, K. L., Goldmakher, G. V., Hacke, W., Kidwell, C. S., Kloska, S. P., Köhrmann, M., Koroshetz, W., Lee, T. Y., Lees, K. R., Lev, M. H., Liebeskind, D. S., Ostergaard, L., Powers, W. J., Provenzale, J., Schellinger, P., Silbergleit, R., Sorensen, A. G., Wardlaw, J., Wu, O., and Warach, S. (2008). Acute stroke imaging research roadmap. Stroke 39, 1621-1628.

Conflict of Interest Statement: The authors declare that the research was conducted in the absence of any commercial or financial relationships that could be construed as a potential conflict of interest.

Received: 10 February 2011; accepted: 09 May 2011; published online: 27 May 2011.

Citation: Frendl $A$ and Csiba L (2011) Pharmacological and nonpharmacological recanalization strategies in acute ischemic stroke. Front. Neur. 2:32. doi: 10.3389/fneur.2011.00032

This article was submitted to Frontiers in Stroke, a specialty of Frontiers in Neurology.

Copyright $\odot 2011$ Frendl and Csiba. This is an open-access article subject to a nonexclusive license between the authors and Frontiers Media SA, which permits use, distribution and reproduction in other forums, provided the original authors and source are credited and other Frontiers conditions are complied with. 